\title{
Journal of Research in Engineering and Applied Sciences \\ DESIGN ELEMENTS OF MOBILE APPS TO BE USED AS SUPPLEMENTS IN A TYPICAL INTRODUCTORY ENGINEERING ANALYSIS COURSE
}

\author{
S. R. Subramanya \\ Professor, School of Engineering and Computing,National University \\ San Diego, CA 92123, USA \\ (E-mail : ssubramanya@nu.edu)
}

\begin{abstract}
Mobile Apps have tremendous potential for use as very effective supplements to the exiting learning modalities in an introductory Engineering Analysis course. In this article we consider the general nature of a typical introductory Engineering Analysis courses and derive elements of design which are expected to make the mobile Apps intended for use as supplements to such a course more effective. We enumerate the elements of the nature and inherent characteristics of typical introductory Engineering Analysis course, and characteristics of the mobile devices and mobile users. We then present the design aspects and desired salient features of mobile Apps intended for uses as supplements in a typical introductory Engineering Analysis course, and the elements of user experience (UX) of such an App. We believe that several of these design elements could be adapted across several different courses and disciplines.
\end{abstract}

Keywords: Mobile Apps, Introductory Engineering Analysis course, Design elements of Apps, User Experience

\section{Introduction}

Since the introduction of Apple's App store and Google's Android Market (now Google Play) around the middle and late part of 2008, the applications (commonly called Apps) available for the smart phones and tablets have surpassed 1.5 Million Apps in Apple App Store, and 1.6 Million Apps in Google Play (as of June 2015 per "statistica.com"), and the number of cumulative downloads have exceeded 100 Billion for both categories, and they continue to grow. Needless to say, these Apps have had phenomenal impacts on our lives in a short time.

Although the mobile Apps span a diverse variety of areas and applications, there has been a paucity of Apps as course supplements in the higher education domain. There are tremendous opportunities in higher education to leverage the mobile Apps for smartphones and tablets to serve as supplements to traditional lectures and textbooks, contributing to the enhancement of the effectiveness of learning/teaching beyond the class room. The important thing to note is that such mobile Apps are not replacements for classroom lectures and textbooks, rather supplements which fill several gaps in the learning process.

In this article, we present the design elements of mobile Apps which act as supplements in a typical introductory Engineering Analysis course. Such an App needs to take into account (i) the inherent characteristics of Engineering Analysis, (ii) the pedagogical issues, (iii) the characteristics of mobile devices and users, and (iv) user experience aspects of mobile Apps.

A mobile App which is proposed to be used as a supplement in a typical introductory Engineering Analysis course needs to take into account several factors across different dimensions, as shown in Fig. 1. These are (a) the specific characteristics of engineering analysis; (b) mobile device and user characteristics; (c) pedagogical factors; (d) user experience (UX) factors.

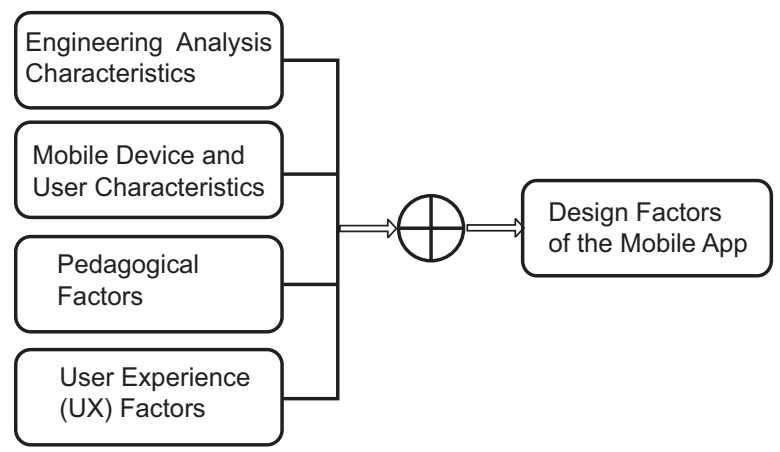

Fig. 1: Major dimensions to be considered in deriving the design factors of a mobile App supplement in an introductory engineering analysis course 
Some of the characteristics of a typical introductory Engineering Analysis course are that they involve: (a) quantitative elements (things are very well defined and not much room for qualitative, subjective, or ambiguous judgments), (b) significant computations, (c) well-defined arguments, proof methods, and derivations to establish conclusions from a set of premises, (d) building upon already established facts and truths, etc.

Some of the pedagogical issues to be supported in a typical introductory Engineering Analysis course are: (a) independent thinking, (b) analytical skills, (c) building on existing proficiencies, (d) development of mathematical processes, (e) mathematical justification /argumentation, (f) abstraction, (g) generalization, (h) tools and representations, etc.

Some of the major user interface / user experience factors to be considered are: (a) Fonts and sizes, (b) colors, (c) contrasts, (d) audio elements, (e) interactions, (f) immersiveness, (g) use and mapping of realworld metaphors, etc. These need to be designed taking into account the mobile device constraints and user characteristics such as, (a) limited screen sizes of devices, (b) limited interaction modes on devices, (c) changing contexts of mobile users, (d) limited attention spans of mobile users, etc.

Incorporation of the design elements developed in this article into mobile Apps intended as supplements in an introductory engineering analysis course is expected to be not just a platform for solving problems and getting answers, but to provide a fun and creative environment for learning engineering analysis. A well-designed App makes it engaging for the students, lowering their effort needed to understand concepts, while leveraging the instructors' efforts in conveying hard and abstract concepts. This facilitates an enhanced teaching and learning experience.

\section{Related work}

Even before the emergence of smartphone Apps, there were a few initiatives in using PDAs
(Personal Digital Assistants) and WiFi-enabled mobile Laptops as learning aids. A few samples of those works are given in (Sharples, 2002; Sharples, 2005; O'Malley, Vavoula, Glew, Sharples, \& Lefrere, 2003). Several of the discussions and results presented in some of these early efforts are valid even in today's context of Smartphone and mobile Apps.

The rapid pace of development of computing, Internet, and mobile technologies and their tremendous impacts on education domain have necessitated new thinking in the development of content, teaching, and learning. New pedagogical challenges in engineering education are presented in (Auer, M.E., Dobrovska, D., \& Edwards, A., 2011). Considerable efforts studying the emergence of mobile technologies, current and (near) future trends are underway. A sample of such work can be found in (Ting, Y. L., 2005). The adoption of mobile technologies in learning environments and some of the design requirements are given in (Parson, D., Ryu, H., \& Cranshaw, M., 2006; Rene, C.J. \& Valdes, C.M., 2007). The recent surge in the development of Apps for smartphones has given a new impetus to several mobile learning related initiatives. These have spanned several areas such as (a) development of mobile content and applications (Zhao, X. \& Okamoto, T., 2008), (b) research into pedagogical issues in using mobile devices/applications in learning (Bransford, J. D., Brown, A. L., \& Cocking, R. C., 2000; Fraser-Abder, P. \& Wallace R. J., 2008), (c) study and evaluation of the effectiveness of mobile Apps in learning (Percival, J. \& Percival, N., 2008), etc.

In (O'Malley C., et. al., 2003) some guidelines for learning in mobile environment are given, including defining mobile learning in terms of a flexible model to enable developers, tutors, and learners to identify learning practices and effective pedagogies, and identifying key elements unique to mobile learning. The effectiveness and usefulness of mobile technologies in augmenting traditional teaching methods and in increasing the student engagement, motivation, and interaction is given in (Callaghan, Harkin, McGinnity, Woods, \& Harrison, 2006). In (Percival, J. \& Percival, N., 2008), it is shown that the value Vol. 01, Issue 02, April 2016 
propositions for engineering and liberal arts programs are significantly different.

A brief summarization of some of the literature related to mobile learning is given in (Cobcroft, Towers, Smith, \& Bruns, 2006). A survey of perceptions by students of mobile learning and how it might enhance their present learning capabilities is given in (Vate-U-Lan, 2008). The significance and challenges of implementing mobile learning of mathematics for primary school students as a means of supplementing traditional classroom teaching and learning has been discussed in (Mahamad, Ibrahim, \& Taib, 2010; Michal \& Ben-Zaken, 2004; Zhao \& Okamoto, 2008). A study done in (Vavoula 2005) reports that considerable amounts of learning taking place outside of classrooms, and not necessarily associated with physical movement.

Concept learning has been shown to be very important in science and engineering (Engelhardt \& Beichner, 2004; Mazur, 2007; Steif, \& Hansen, 2006). Reports of several work related to pedagogical issues in science, math, and technical education have been compiled in (Fraser-Abder, P. \& Wallace R.J., 2008). More work in these directions are needed, since although there have been numerous studies and works related to concepts learning, research on conceptual learning in engineering has been somewhat limited. Drawing on fundamental research by cognitive psychologists and applied research by science educators, an analysis of the sources of difficulties in learning engineering concepts is given in (Streveler, Litzinger, Miller, \& Steif, 2008).

\section{Smartphone App as supplements in introductory engineering courses}

Although there have been several Apps used in academia, they are mostly for administrative purposes such as institutional and departmental information, maps and directions, information about programs and courses, calendar of events, etc. However, there has not been widespread use of smartphone Apps as learning supplements in higher education, especially in engineering courses. There is a tremendous opportunity to develop suitable Apps which could act as powerful catalysts and supplements for learning the concepts in Engineering courses. We envision a broad acceptance and use of customized mobile apps in the near future to enhance student engagement and learning effectiveness. Given the pace of development of Mobile Apps, it won't be too long before the availability of numerous Apps, both developed in-house by higher educational institutions and also by third-party developers.

\section{Course content in a typical introductory engineering analysis course}

There are numerous textbooks and syllabi adopted in introductory engineering analysis courses. The topical coverage in a typical introductory engineering analysis course based on (Hagen 2014) is shown in Fig. 2. It starts with elements of (general) analysis methodology (the details of which is given in the next section). Then, elements of mechanics, thermodynamics, electric circuits, and fluid mechanics are covered. In each of these areas, the concepts are provided with the corresponding mathematical notations and formulations. Several examples are provided followed by exercise problems. As applicable, data analysis will be involved. Both graphing and statistical techniques are used in the data analysis.

During a typical introductory engineering analysis course students are required to use critical thinking skills, problem classification, use of physical facts and relations, as well as

\section{Coverage in a Typical Introductory Engineering Analysis Course}

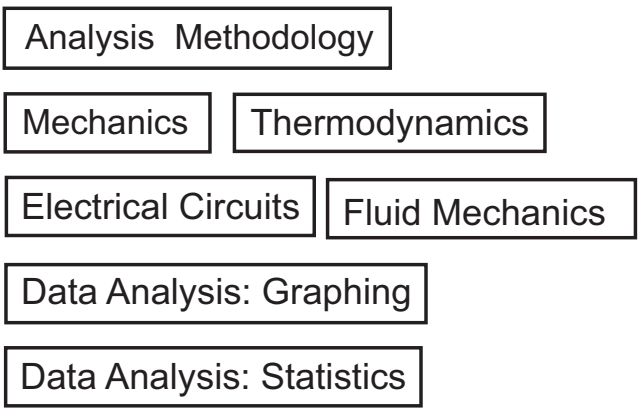

Fig. 2 : Topics covered in a typical introductory engineering analysis course 
experimentations, data collections, and analysis. Often students manage to complete these tasks with an aid of a scientific or graphing calculator and laptops with a number of general and specialized software packages which facilitate problem formulation, analysis, and synthesis. It must be noted that calculators are only computational tools and by no means tools for teaching mathematical or engineering concepts. The computing power, ease-of-use, and convenience of portability of mobile devices are clearly more appealing than carrying a laptop. Mobile apps are well suited for addressing specific, focused, topics in an engineering analysis course.

\section{General engineering analysis procedure}

The general analysis procedure is a well-established procedure in the modeling and solving of engineering problems. The steps involved in this procedure are shown in Fig. 3.

\section{Steps in General Analysis Procedure}

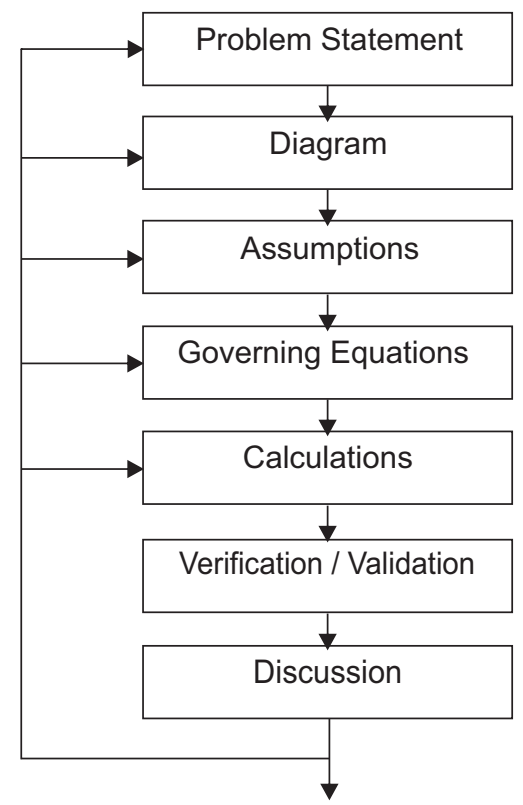

Fig. 3 : The major steps involved in the general analysis procedure
It starts with a verbal problem statement. The next step is the development of a diagram illustrating the problem using standard notations (specific to the problem domain mechanics, circuits, etc.). This is followed by clearly laying out the set of assumptions. Note that the real-world problems in most cases are extremely complex, and a suitable, simplified model is developed. The assumptions are crucial in clearly specifying the model. Subsequently the governing equations corresponding to the model are derived. These equations are then solved using known methods to obtain the solutions to the problem. The solving of the governing equations corresponds to the calculations/computations in the diagram. The solution obtained is as good as the equations which were developed for the model. The solution is then verified / validated to see if it is meaningful and relevant to the original problem statement. If so, it is accepted and used. Otherwise, any of the earlier steps of problem statement to calculations is revisited and revised / refined and the steps are repeated until the solution is satisfactory.

\section{Key skills to be learnt in a typical introductory engineering analysis course}

The previous section outlined the general engineering analysis procedure. The key skills expected to be learnt in a typical introductory engineering analysis course are shown in Fig. 4. The problem formulation is an extremely important first step in which the real-world problem is described formally in a combination of words and mathematical formulae and equations. Even a slight flaw in this step may ultimately lead to wrong solutions and undesirable outcomes. The next step is problem analysis which involves developing the inputoutput relations and identifying the various parameters involved in the problem and its solution. In the next step, the governing equations for the model, and the components and interactions are developed. It is very important to develop good conceptual thinking linking the equations to 'behaviors' in the external world. 


\section{Key Skills Expected to be Learnt in Introductory Engineering Analysis}

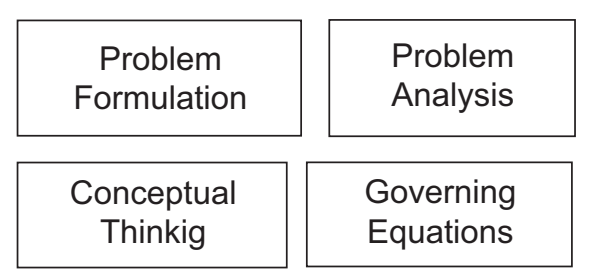

\begin{tabular}{|c|}
\hline $\begin{array}{c}\text { Analytical Problem } \\
\text { Solving }\end{array}$ \\
\hline $\begin{array}{c}\text { Model Development } \\
\text { and Refinement }\end{array}$ \\
\hline $\begin{array}{c}\text { Relationships among } \\
\text { System Parameters }\end{array}$ \\
\hline
\end{tabular}

Fig. 4 : Expected skills to be learnt in a typical introductory engineering analysis course

The analytical problem solving involves understanding a problem and making the right of a variety of mathematical techniques (algebra, trigonometry, calculus, differential equations, etc.) to develop a solution. Since most real-world problems are highly complex and not easily amenable for analytical solutions, models of the real-world problems are developed. The components in the model and their interactions need to be expressed in relatively simple terms enabling easy understanding of the cause-effect behaviors, and subsequent solution development. Oftentimes this is an iterative process wherein a very simple and crude model for the real-world problem is developed, and is subsequently refined to make it resemble the original problem better. This avoids being overwhelmed by the complexity and enables step-wise refinements. Understanding of the relationships between the system parameters provides better insight into the overall behavior of the system and provides opportunities for developing solutions subject to various constraints.

\section{Expected benefits of the mobile App course supplement}

The expected benefits of a well-designed mobile App supplement in a typical introductory engineering analysis course is summarized in Fig. 5, and briefly described below.

Since the Apps are inanimate, the slow learners would not have hesitation to use them repeatedly to learn or reinforce concepts they have particular difficulty with. This, combined with the entertaining/engaging aspect, would be a motivating factor for using the App for learning. The incorporation of appropriate positive feedback would provide encouragement in addition to motivation.

Repetitious use of content will enable reinforcing abstract concepts. Due to limited times in class rooms, repetitions may not be possible/practical (beyond a limited number), and without an App, the only recourse for motivated students are self-reading, discussion with classmates, tutoring, etc. Mobile Apps facilitate repetitious use enabling retention.

Expected Benefits of Mobile Apps as Supplements in a typical Introductory Engineering Analysis Course

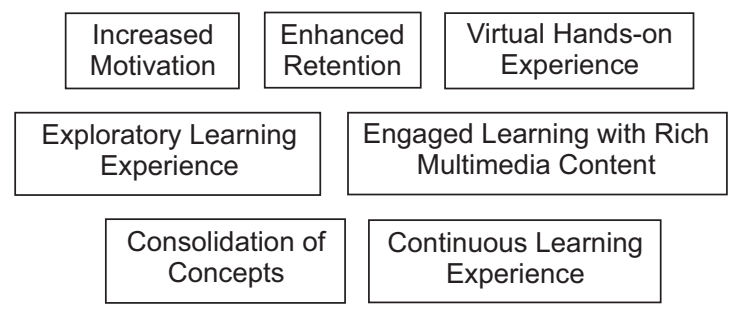

Fig. 5 : Expected benefits of a Mobile App supplement in introductory engineering analysis course

The Apps can be designed making use of judicious combinations of text, graphics, audio, video, and animation to provide virtual handson experience. Mobile Apps provide by 'anytime', 'any-where' access supporting continuous learning. Apps, by their interactive and media rich nature, would also facilitate exploration and experimentation, which are highly essential to comprehend and gain insight into abstract concepts.

The Apps could be designed to be exploratory (as opposed to being limited to a narrow scope) by incorporating numerous related content, and by providing support for non-linear navigation, cross-referencing, and even making cross-disciplinary connections, as appropriate. 


\section{Desired salient features of the mobile App course supplement}

We have identified several desired salient features of a mobile App used as a supplement to an introductory engineering analysis course are shown in Fig, 6 and brief descriptions of each of these are given below.

Varieties of figures and examples related to concepts, from sources other than the textbook, are desirable to facilitate different views. Many times, the expositions of the same concept are done in different ways in different books and other sources. Inclusions of these would cater to different learning styles. Material from other sources (ex. Wikipedia) would be immensely useful in filling in several details and up-to-date content not found in a textbook.

The video clips consist of portions of actual lectures related to exposition of concepts, or derivations of complex equations, or working out examples. These may be collected from multiple sources. While the textbook content is static, and is usually hard to follow by students on their own, a video clip is dynamic and would convey concepts in a way that would be much easier to follow.

Interactivity is easy to build into a mobile App. This can be advantageously used to provide a step-by-step aid for concept learning and problem solving. Animation and graphics facilitate the ease of understanding of complex concepts and the interrelations between multiple variables of a system.

In several Engineering courses, laboratories are expensive to establish and maintain. With the advances in computing hardware and

Desired Salient Features of Mobile Apps as Supplements for a typical Introductory Engineering Course

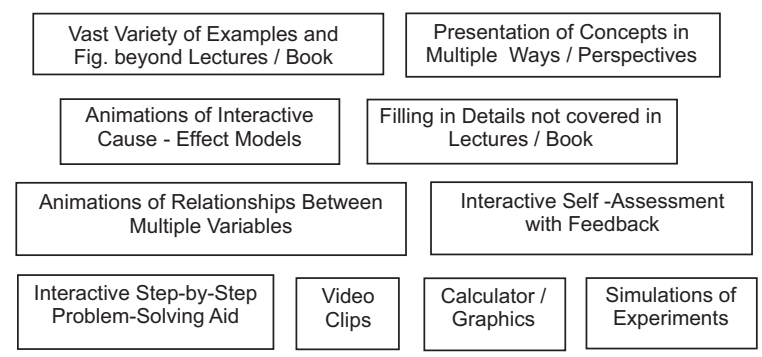

Fig. 6 : Desired salient features of a Mobile App supplement in introductory engineering analysis course software, simulation has become a costeffective alternative. It also provides flexibility in terms of making changes and upgrading. The simulation component in the mobile App provides supplemental learning experience of experimentations and sights into workings of systems.

Computations are the core of the working of mathematical and engineering systems. The calculator and graphics component facilitates the easy computation of various formulas and solving equations, and presentation of results graphically, as applicable.

The assessment component draws upon a large pool of questions with varying difficulty levels. The self-assessment test presents questions to the learner in a progressive manner, with questions of gradually increasing difficulty. Based on the answers provided, the App (system) determines the level of comprehension or difficulty areas of the learner, and focus more on those areas by providing more examples and assessment questions as needed. Thus it may have some form of personalization built in in the form sequence of questions suited to the individual learners in order to reinforce the weak areas.

\section{Major user experience (UX) factors to be considered in the design of the mobile App course supplement}

The approaches to usability issues with respect to mobile learning in the context of PDAs which have been compiled in (Kukulska-Hume, 2007) are relevant in the Smartphone context as well. The "Five Es" of usability of a product according to (Quesenbery) are very much relevant to Apps. Since the usability of Apps is very crucial from a user's perspective. A product is usable when it is (a) effective, (b) efficient, (c) engaging, (d) easy to learn, and (f) error tolerant. It is effective when it affords goal accomplishment with minimum effort; efficient when it allows rapid task completion with few errors; engaging when it offers enjoyable day-to-day operation; easy to learn when it supports rapid initial skill acquisition and expanded skill development with experience; error tolerant when it prevents 
errors and supports error recovery.

Special considerations must be given to the design of content and user interfaces for mobile devices and applications. Some of the major content-related issues that need to be addressed in mobile environments are presented in (Subramanya, \& Yi, 2005). In (Subramanya, 2012) a model and some issues for the consumption experience of digital educational content have been proposed. The proposed model is expected to aid the designers and developers of digital educational content and services in enhancing the content consumption experience.

The user experience (UX) factors that we propose to be considered in the design of the mobile App supplement are summarized in Fig. 7, and are briefly described below.

\section{Major User Experience Factors of the Mobile App for Successful Adoption}

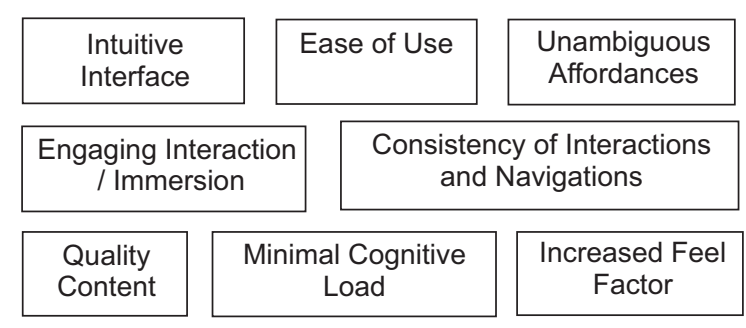

Fig. 7 : Major user experience (UX) factors of a Mobile App supplement

Intuitive interface. An intuitive interface does not require detailed instructions and does hardly have any learning curve. The elements of the interface are thoughtfully designed and judiciously laid out. This makes it 'natural' for users to use.

Ease of use. An easy-to-use interface is important for the App to be appealing. The interface should hide the underlying complexities of functions and operations to enable the users to use the App effectively to accomplish the intended uses. The average number of (atomic) user actions (ex. key clicks / taps) to accomplish a task is minimal.

Unambiguous affordances. An affordance is a property of an object, or an environment, which allows an individual to perform an action.
In the context of human-computer interaction (HCI) it indicates the easy discoverability of possible actions. In the case of mobile Apps, the affordances should be unambiguous to enable selection of actions to achieve intended operations, and eliminate/minimize the number of backtracking.

Engaging interaction/immersion. The interactions should be designed to be engaging and immersive to sustain the interest of the user to the point of finishing the tasks. This is especially important considering the fact that the attention spans of mobile users are rather short.

Consistency of interactions and navigations. The interactions and navigations should be consistent across tasks and functionalities. This makes App easy to learn and to use, with reduced cognitive burden.

Quality content. The quality of content is a crucial factor. Although the UI and UX are well designed, a poor quality content would not sustain the interest of the user and would not contribute to effective learning.

Minimal cognitive load. The average number of levels in the navigation to accomplish a given task / functionality contributes to the cognitive load. Minimal cognitive load is extremely important for acceptance of mobile Apps, especially when used as supplement to learning. With a low cognitive load, the user can focus more on the content and the learning aspects.

Increased feel factor. The 'feel factor' is abstract and not easily quantifiable. It generally refers to the overall experience of a user using a gadget or system. In the context of a mobile App, it refers to the unobtrusive way the App can be used to accomplish the main tasks without the user having to struggle or spend more than the minimum amount of the required time and effort.

\section{Conclusions}

The mobile Apps are just beginning to make inroads in the higher education domain, and 
there is tremendous potential for Apps to supplement traditional course work and textbooks. In this article, we outlined the nature of an introductory engineering analysis course, and the expected benefits, the desirable salient features, and the user experience factors that must be considered in a mobile App for use as supplement in a typical introductory engineering course. Well-designed Apps have the potential to enhance the effectiveness of teaching by acting as supplements, and to provide effective learning experience.

\section{References}

[1] Auer, M.E., Dobrovska, D., \& Edwards, A. (2011). New Pedagogic Challenges in Engineering Education and the Answer of IGIP, 38th ASEE/IEEE Frontiersin Education Conference, Rapid City, SD.

[2] Bransford, J.D., Brown, A.L., \& Cocking, R.C. (Eds.) (2000). How People Learn: Brain, Mind, Experience, a n d School, National Academy Press, Washington, DC.

[3] Callaghan, M. J., Harkin, J., McGinnity, T. M., Woods, D. N., \& Harrison, B. (2006). Technology Supported Pedagogy in a Flexible, Mobile, Learning Environment, Proc. Association of Pacific Rim Universities Conference on Online Distance Learning and Internet, Tokyo.

[4] Cobcroft, R. S., Towers, S. J., Smith, J. E., \& Bruns, A. (2006). Mobile learning in review: Opportunities and challenges for learners, teachers, and institutions ( $\mathrm{p} \mathrm{p}$. 21-30). Proc. Online Learning and Teaching (OLT) Conference, Queensland University of Technology, Brisbane.

[5] Engelhardt, P.V. \& Beichner, R.J. (2004). Students' Understanding of Direct
Current Resistive Electrical Circuits, American Journal of Physics, 72(1), 98-115.

[6] Fraser-Abder, P. \& Wallace R.J., (Eds.). (2008). Pedagogical Issues in Science, Math, and Technical Education, Vol. 3 (ISBN: 0-615-12634-0).

[7] Hagen, K.D. (2014). Introduction to Engineering Analysis (Fourth Ed.), (ISBN: 978-0-13-348508-0), Pearson.

[8] Kukulska-Hume, A. (2007). Mobile Usability in Educational Contexts: What have we Learnt?, International Review of Research in Open and Distance Learning, 8(2), (ISSN: 1492-3831).

[9] Mahamad, S. Ibrahim, M.N. \& Taib, S.M. (2010). M-Learning: A New Paradigm of Learning Mathematics in Malaysia, International Journal of Computer Science \& Information Technology, 2(4), 76-86.

[10] Mazur, E. (2007). Peer Instruction, Prentice-Hall.

[11] Michal, Y. \& Ben-Zaken, O. (2004). Mobile Phones in Education: The Case of Mathematics, The Institute for Alternatives in Education, University of Haifa.

[12] O'Malley, C., Vavoula, G., Glew, J. P., Sharples, M., \& Lefrere, P. (2003).

[13] Guidelines for Learning / Teaching / Tutoring in a Mobile Environment, Report of MOBILearn Project (UoN, $\mathrm{U}$ o B , $\mathrm{O} \mathrm{U} / \mathrm{D} 4.1 / 1.0$ ) (www.mobilearn.org), 1-57.

[14] Parson, D., Ryu, H., \& Cranshaw, M. (2006). A Study of Design 
Requirements for Mobile Learning Environments, Proc. 6th International Conference on Advanced Learning Technologies.

[15] Percival, J. \& Percival, N. (2008). Engineering Students' Perceptions of Mobile Learning, Proc. of the World Congress on Engineering and Computer Science, San Francisco.

[16] Quesenbery, W. The Five Dimensions of Usability, in M. J. Albers \& B. Mazur (Eds.), Content and Complexity: Information Design in Technical Communication, Mahwah, NJ: Lawrence Erlbaum Associates.

[17] Rene, C.J. \& Valdes, C.M. (2007). Are you Ready for Mobile Learning, Educase Quarterly, 2.

[18] Sharples, M. (2002). Disruptive Devices: Mobile Technology for Conversational Learning, International Journal of Continuing Engineering Education and Life Long Learning, 12(5/6), 504-520.

[19] Sharples, M. (2005). Learning as Conversation: Transforming Education in the Mobile Age, Proc. of Conference on Seeing, Understanding, and Learning in the Mobile Age, Budapest, 147-152.

[20] Steif, P.S., \& Hansen, M.A. (2006). Feeding Back Results from a Statics Concept Inventory to Improve Instruction, Proc. American Society for Engineering Education Annual Conference, Chicago, IL.

[21] Streveler, R. A., Litzinger, T. A., Miller, R. L. and Steif, P. S. (2008), Learning Conceptual Knowledge in the
Engineering Sciences: Overview and Future Research Directions. Journal of Engineering Education, 97: 279-294.

[22] Subramanya, S.R., \& Yi, B.K. (2005). Mobile Content Provisioning - Major Issues, Wireless World Research Forum, Paris.

[23] Subramanya, S.R. (2012). Enhancing Digital Educational Content Consumption Experience, The Journal of Research in Innovative Teaching, 5(1), 106-115.

[24] Ting, Y. L. (2005). Mobile Learning: Current Trends and Future Challenges, Proceedings of the Fifth IEEE ICALT.

[25] Vate-U-Lan, P. (2008). Mobile Learning: Major Challenges for Engineering Education, 38th ASEE/IEEE Frontiers in Education Conference, Saratoga Springs, NY.

[26 Vavoula, G.N. (2005). A Study of Mobile Learning Practices, Report of MOBILearn Project (D4.4) (www.mobilearn.org).

[27] Zhao, X. \& Okamoto, T. (2008). A Personalized Mobile Mathematics Tutoring System for Primary Education, Journal of the Research Center for Educational Technology, 4(1). 